\title{
Effect of cold plasma on degradation of organophosphorus pesticides used on some agricultural products
}

\author{
Seyyedeh Mahbubeh Mousavi ${ }^{1}$, Sohrab Imani ${ }^{1 *}$, Davoud Dorranian ${ }^{2}$, Kambiz Larijani $^{3}$, \\ Mahmoud Shojaee ${ }^{1}$ \\ ${ }^{1}$ Department of Entomology, Science and Research Branch, Islamic Azad University, Tehran, Iran, 1477893855 \\ ${ }^{2}$ Department of Plasma Physics Research Center, Science and Research Branch, Islamic Azad University, Tehran, Iran, \\ 1477893855 \\ ${ }^{3}$ Department of Organic Chemical, Science and Research Branch, Islamic Azad University, Tehran, Iran, 1477893855
}

Vol. 57, No. 1: 25-35, 2017

DOI: 10.1515/jppr-2017-0004

Received: April 27, 2016

Accepted: February 1, 2017

*Corresponding address:

imanisohrab@gmail.com

\begin{abstract}
This study investigated the potential effect of cold plasma on reducing residues of pesticides diazinon and chlorpyrifos in apples and cucumbers and its effects on property of products. Two separate concentrations of each pesticide with 500 and 1,000 ppm were prepared and the samples were inoculated by dipping them into the solutions. All samples treated with pesticides were exposed to cold plasma in a monopole cold plasma apparatus (DBD) run at 10 and $13 \mathrm{kV}$ voltages. Liquid-liquid extraction (LLE) was used to remove pesticide residues from the samples. Eventually, high-performance liquid chromatography (HPLC) was used to measure the amount of pesticides in the samples. Also, to investigate generated metabolites, extracts were injected into a GC/MS apparatus. In addition, the effects of cold plasma on humidity, tissue hardness, color and the sugar percentage of products were analyzed. The results revealed that treatment of samples with cold plasma considerably reduced pesticide residues without leaving any traces of harmful or toxic substances. Furthermore, it did not have any undesirable effects on the color and texture of the samples. The efficiency of this method increased with higher voltage and longer exposure time. In general, the best results were obtained by the combination of $500 \mathrm{ppm}$ concentration, $10 \mathrm{~min}$ exposure and $13 \mathrm{kV}$ voltages. The residues of diazinon were reduced better than the residues of chlorpyrifos. Apples were detoxified much better than cucumbers. Also, cold plasma treatment transformed diazinon and chlorpyrifos pesticides into their less toxic metabolites. The results showed that with increased voltage and longer exposure time, cold plasma caused few changes in moisture and glucose content, texture hardness and color of products. There were no significant difference between treated samples and control in all treatments.
\end{abstract}

Key words: chlorpyrifos, cold plasma, diazinon, detoxification

\section{Introduction}

The use of organophosphorus (OP) pesticides as an alternative to organochlorine compounds all over the world have consequences on both human health and the natural ecosystems. Organophosphorus pesticide residues can be found in some agricultural products and natural waters, due to their extensive use and moderate persistence (Bai et al. 2006; Ambrus 2009; Hernandez-Borges et al. 2009). In order to avoid adverse effects of OP pesticide residues on the environment, effective methods to remove and degrade pesticide residues from fresh agricultural products are seriously necessary. Many sterilization methods such as conventional thermal methods, ozonation, UV, ultrasonic and ionizing radiation, photolysis and hydrolysis have been used for the degradation of OP pesticide residues. However, these techniques have low efficiency, potential hazards and are costly (Le Person et al. 2007; Oancea and Oncescu 2008; Ormad et al. 2008).

Recently, the use of cold plasmas operating at ambient air pressure (or other operating gases and gas 
mixtures) is a relatively novel technique for the decontamination of fresh foods and food processing surfaces. Misra et al. (2011) and Niemira (2012) reviewed the fundamentals of cold plasma and its application to decontamination of foods. There are some reports about the efficiency of cold plasma plasmas to inactivate microorganisms including bacteria, bacterial spores, fungi, and biofilms (Feng et al. 2009; Koban et al. 2010) and to degrade bio-macromolecules such as proteins and saccharides (Deng et al. 2007; Bayliss et al. 2009).

Plasma is a glow flow composed of very reactive chemical species such as charged particles, free radicals and some radiation which occurs when a gas is in contact with an electrical discharge. Cold atmospheric plasma, referred to as plasma, is generated under mild conditions of temperature (sometimes ambient conditions) (Fernández and Thompson 2012). The food industry prefers a temperature around $30-60^{\circ} \mathrm{C}$ because of the low energy required to generate it, and this is the temperature of cold plasma (Misra et al. 2011). Plasma can inactivate the microorganisms by heat, charged particles, electric fields, UV photons and some reactive species such as atomic oxygen, metastable oxygen molecules, ozone and hydroxyl radicals, which are commonly found in a gas discharge (Georgescu et al. 2010).

Unlike microbiological decontamination limited research has been done on the successful degradation of OP pesticides by cold plasma and the degradation mechanisms are not fully understood. The degradation of dichlorvos and omethoate organophosphorus pesticides sprayed onto maize samples was studied by Bai et al. 2009. Recently, Bai et al. (2010) also demonstrated the successful degradation of dichlorvos pesticides coated on glass slides. Kim et al. (2007) reported the decomposition of paraoxon and parathion with an atmospheric pressure and radio-frequency plasma.

Apple and cucumber are the most commonly used agricultural products in Iran and throughout the world. To control the pests that attack these products, a lot of pesticides such as diazinon and chlorpyrifos are applied by growers in orchards and greenhouses. These two pesticides have undesirable effects on the environment and human health. Therefore, consumers are at risk from residues of these pesticides. In this study we evaluated the potential effects of cold plasma in reducing residues from pesticides such as diazinon and chlorpyrifos in apples and cucumbers.

\section{Materials and Methods}

\section{Preparing standard concentrations of pesticides}

Pesticides diazinon and chlorpyrifos from Sigma Corporation were used in these experiments. The samples of standard concentrations of pesticides had $99.9 \%$ purity. One mg from each standard was dissolved in $1 \mathrm{cc}$ ethyl acetate separately, and then different concentrations were prepared, namely $0.1,1,10,100$ and 1,000 ppm, which were then injected to HPLC.

\section{Cold plasma Monopole Dielectric Barrier Discharge (DBD) device}

The device shows the volume and has a screen in its front panel. The output voltage can be changed between 30 to $100 \%$ by volume. The voltages in 77 and $100 \%$ are 10 and $13 \mathrm{kV}$, respectively. The cold plasma was formed by creating an electric field with a high voltage power supply and reducing the distance between two electrodes. This device is a plasma generator for work under atmospheric pressure (air mixture). In this experiment the frequency of the device was constant in $13 \mathrm{kHz}$, and two voltages including 10 and $13 \mathrm{kV}$ were considered as variables and in all experiments, the distance between two electrodes was $7 \mathrm{~mm}$ (Fig. 1).

\section{Preparation of fruits and vegetables}

The fresh fruit including apple and cucumber was prepared from organic product centers. Slices of the fruits and vegetables (apple and cucumber: $3 \times 3 \mathrm{~cm}$ square, $0.5 \mathrm{~cm}$ thick) were cut with a knife. The size of the square samples of apple and cucumber was determined by the electrode size of the cold plasma device. All the samples were identical in weight and size.

\section{Experiments}

Two concentrations, 500 and 1,000 ppm, from two pesticides were used separately. The samples of apple and cucumber were dipped in the pesticide solutions for $2 \mathrm{~min}$, then air dried and this procedure was repeated. There were two treatments: exposure to cold plasma and the control without cold plasma. Every sample exposed to cold plasma was introduced to the cold plasma Monopole DBD device with two voltages, 10 and $13 \mathrm{kV}$, for 2, 4, 6, 8 and $10 \mathrm{~min}$. Slices of fruit and vegetables were put in a Petri dish and exposed to the plasma $7 \mathrm{~mm}$ from the exit nozzle of the device. Then we used a HPLC device for analysis of pesticide residues in the samples. Also the obtained extracts were injected into a gas chromatography/mass spectrometry (GC/MS) device to determine the generated metabolites.

\section{Extraction and determination of pesticide residues}

\section{Liquid-liquid extraction (LLE)}

In order to extract the pesticide residues from all of the samples we used LLE. Liquid-liquid extraction, also 

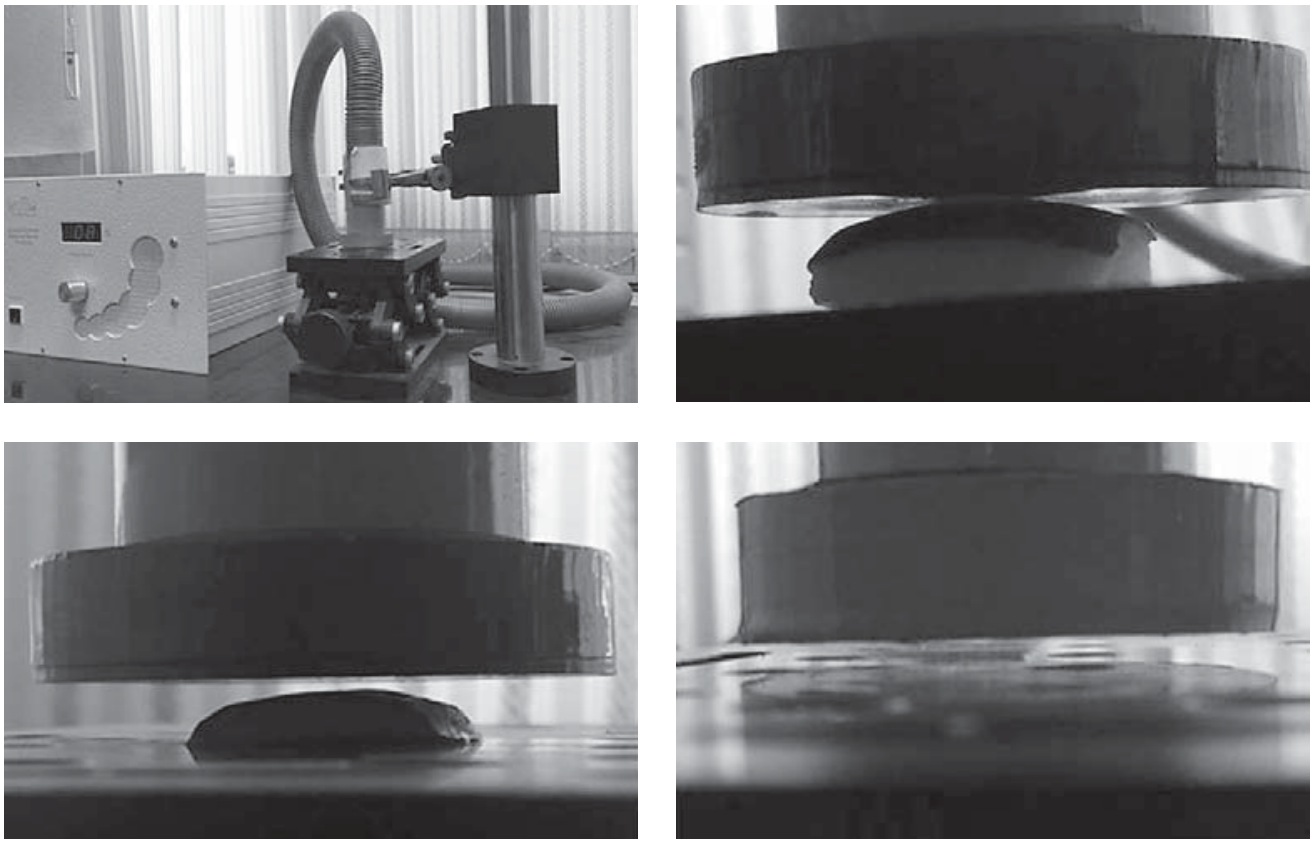

Fig. 1. Cold plasma device with apple and cucumber samples

known as solvent extraction and partitioning, separates compounds based on their relative solubility in two different immiscible liquids, usually water and an organic solvent. It extracts a substance from one liquid into another liquid phase. Separately each sample was pounded in a mortar. In these experiments, every solvent, including ethyl acetate, hexane and acetone, was added to the samples, separately. In the first step, $5 \mathrm{~g}$ of homogenized cucumber and apple samples and $5 \mathrm{ml}$ ethyl acetate were blended inside a container and then shaken for $5 \mathrm{~min}$. Then the container was stabilized until two phases were separated. In the above phase ethyl acetate was removed from the sampler. In the second step, $5 \mathrm{ml}$ hexane was added to the solution and shaken for $5 \mathrm{~min}$. After immobilization of the solution, the above phase (hexane) was removed from the sampler. In the last step, $5 \mathrm{ml}$ acetone was added to the solution and the previous steps were repeated. Finally, in order to concentrate the extracted solutions, they were passed from anhydrous sodium sulfate.

\section{Gas chromatography coupled to mass spectrometry (GC/MS)}

Gas chromatography coupled to mass spectrometry is widely used in the analysis of pesticides that are highly volatile. In order to identify the potentially generated metabolite we used the GC/MS device model 5973 which included MS and capillary column (non-polar) Hp-5MS (Phenyl dimethyl siloxane) $30 \mathrm{~mm}$ in length, $250 \mathrm{~mm}$ in inner diameter and $0.25 \mu \mathrm{m}$ in thickness of immobile phase. The operating conditions were: MSD detector; injection port temperature, $200-220^{\circ} \mathrm{C}$; column oven temperature, $80-160^{\circ} \mathrm{C}$ ramped at $20^{\circ} \mathrm{C}$. $\cdot \mathrm{min}^{-1}$, then $1.0 \mathrm{~min}$ at $160^{\circ} \mathrm{C}$, followed by $10^{\circ} \mathrm{C} \cdot \mathrm{min}^{-1}$ from $160^{\circ} \mathrm{C}$ to $280^{\circ} \mathrm{C}$; helium carrier gas (flow rate of $1.0 \mathrm{ml} \cdot \mathrm{min}^{-1}$ ); with ionization achieved by electron impact at $70 \mathrm{eV}$ in multiple reaction monitoring (MRM) mode and the mass range was 50-500 amu.

\section{Measurement of physical and chemical properties}

A direct drying method was applied to investigate the moisture content of the vegetable and fruit slices after plasma treatment. Fruit and vegetables slices were placed in dried weighing bottles and kept at $105^{\circ} \mathrm{C}$ for at least $7 \mathrm{~h}$ in a drying oven. They were then allowed to cool down to room temperature in desiccators for half an hour and weighed again. The difference in this final weight and the initial weight before drying is the moisture weight. This procedure was repeated in three consecutive cycles until the final and precise weight was obtained and as much moisture as possible was eliminated. The total moisture content was then defined as the difference between the initial weight prior to the first drying cycle and the final weight after the last drying cycle.

Changes in color parameters due to plasma exposure was another property that influence the marking of fruits and vegetables. In order to quantify the color differences of fruit and vegetable slices, the slices were examined with a spectrophotometer, model Xrite Sp-64 with D65 source of light. The device, based on the absorption of light in samples, measures parameters such as L (color transparency), a (green-red) and b (blue-yellow). The data were analyzed using color of control software. Finally the results were reported as the color difference between treated samples and control. 
Another property that is important to the marking of fruits and vegetables is texture hardness. We used a ct3 texture analyzer made in the USA to investigate texture hardness of products that were exposed to cold plasma. We also measured the effect of cold plasma on Brix or solid material dissolved in apple fruits. For this purpose we used an ABBE refractometer. First, the refractometer was calibrated by using a drop of distilled water. Then a drop of the extract of samples was exposed to the device and in front of the light, the number of Brix solid material dissolved in apple fruits was recorded. This number mainly shows the amount of glucose produced within the fruits.

\section{Analysis}

The one-way ANOVA was done in factorial design in a completely randomized design with SPSS14 to analyze the effect of cold plasma on the degradation of organophosphorus pesticide and the means were compared by Duncan's multiple range test.

\section{Results}

\section{Effect of cold plasma on detoxification}

Our results showed that the effects of the main factors such as type of fruit or vegetable, type of pesticide, concentrations, procedure and time on percentage of residue were statistically significant. The effect of type of fruit or vegetable was significant at level $5 \%$, while the effects of other factors were significant with probability of $99(\mathrm{p}<0.001)$. The high value of coefficient of determination $\left(\mathrm{R}_{2}=0.994\right)$ meant that the model was chosen well. This suggested that factors in the model cover more than $99 \%$ of all changes which affect parameters involved in the percentage of
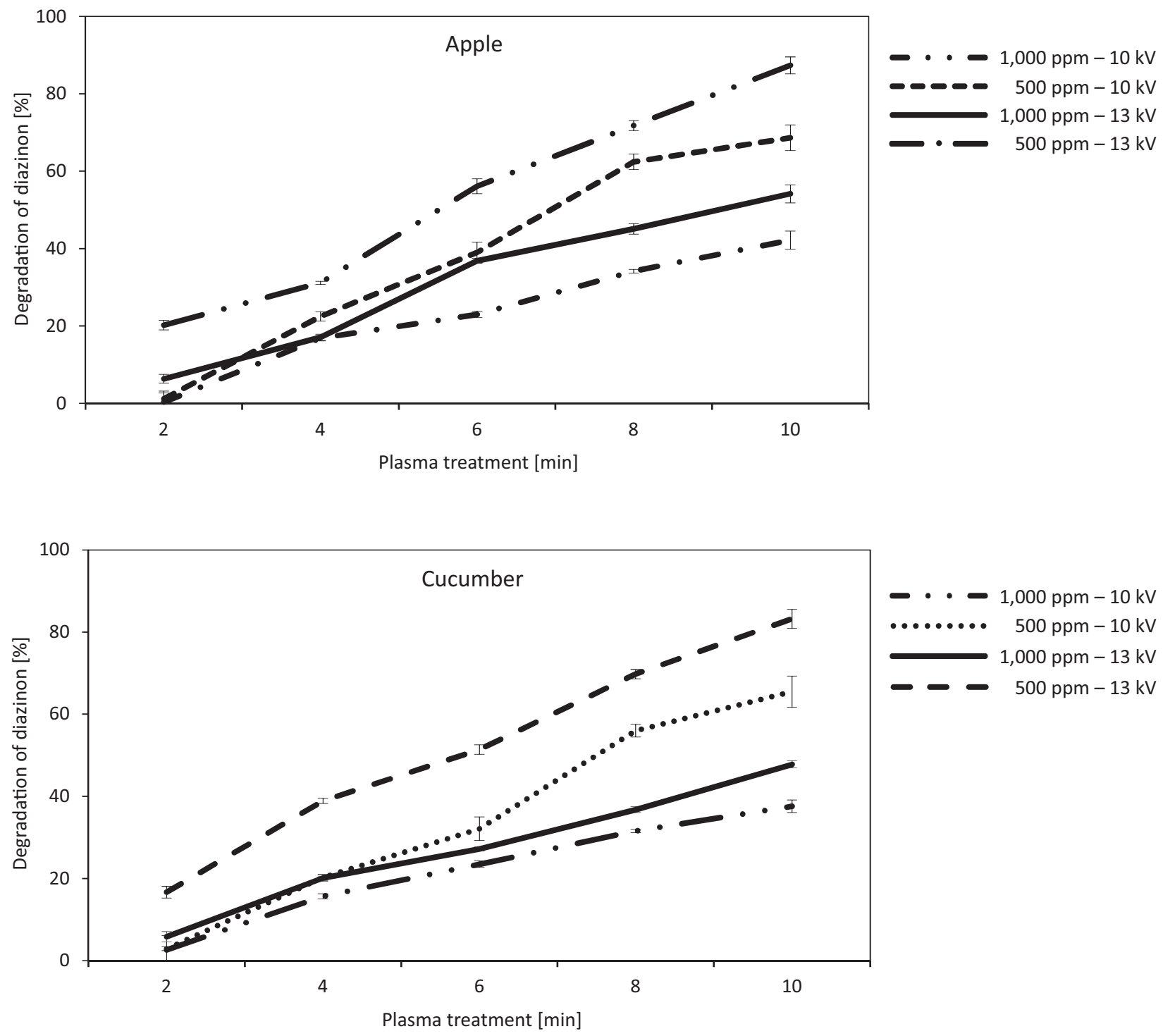

Fig. 2. Effect of the duration of cold plasma treatment on the degradation of diazinon at different voltages in apple and cucumber 
detoxification of pesticide residues and a very small percentage of the variations are caused by random factors (errors).

\section{Percentage of detoxification of diazinon in different products}

According to Figure 2, with longer cold plasma treatment, from 2 to $10 \mathrm{~min}$, the mean percentage of detoxification of diazinon in both concentrations and also both products increased. We found the highest percentage of detoxification with cold plasma treatment in apple for $10 \mathrm{~min}$ for $500 \mathrm{ppm}$ at $13 \mathrm{kV}$ and $10 \mathrm{kV}$. This reduced the residue of diazinon to $87.38 \%$ and $63.67 \%$, respectively. These values for $1,000 \mathrm{ppm}$ at $13 \mathrm{kV}$ and $10 \mathrm{kV}$ were $16.54 \%$ and $18.42 \%$, respectively. Also, the percentage of detoxification of the residue of diazinon in cucumber for $500 \mathrm{ppm}$ at $13 \mathrm{kV}$ and $10 \mathrm{kV}$ was $82.24 \%$ and $65.49 \%$, respectively and for
$1,000 \mathrm{ppm}$ at $13 \mathrm{kV}$ and $10 \mathrm{kV}$ was $79.47 \%$ and $56.37 \%$, respectively.

\section{Percentage of detoxification of chlorpyrifos in different products}

According to Figure 3, with an increase in the time of cold plasma treatment from 2 to $10 \mathrm{~min}$, the mean percentage of detoxification for diazinon in both concentrations and also both products increased. According to our results, the best results for the percentage of detoxification by using cold plasma in apple, for $10 \mathrm{~min}$ for $500 \mathrm{ppm}$ at $13 \mathrm{kV}$ and $10 \mathrm{kV}$ reduced the remaining of diazinon to $86.96 \%$ and $32.55 \%$, respectively. These values for $1,000 \mathrm{ppm}$ at $13 \mathrm{kV}$ and $10 \mathrm{kV}$ were $7.53 \%$ and $44.33 \%$, respectively. Also, the percentage of detoxification of the residue of diazinon in cucumber for $500 \mathrm{ppm}$ at $13 \mathrm{kV}$ and $10 \mathrm{kV}$ was $33.74 \%$ and $8.54 \%$, respectively and for $1,000 \mathrm{ppm}$ at $13 \mathrm{kV}$ and $10 \mathrm{kV}$ was $58.33 \%$ and $33.27 \%$, respectively.
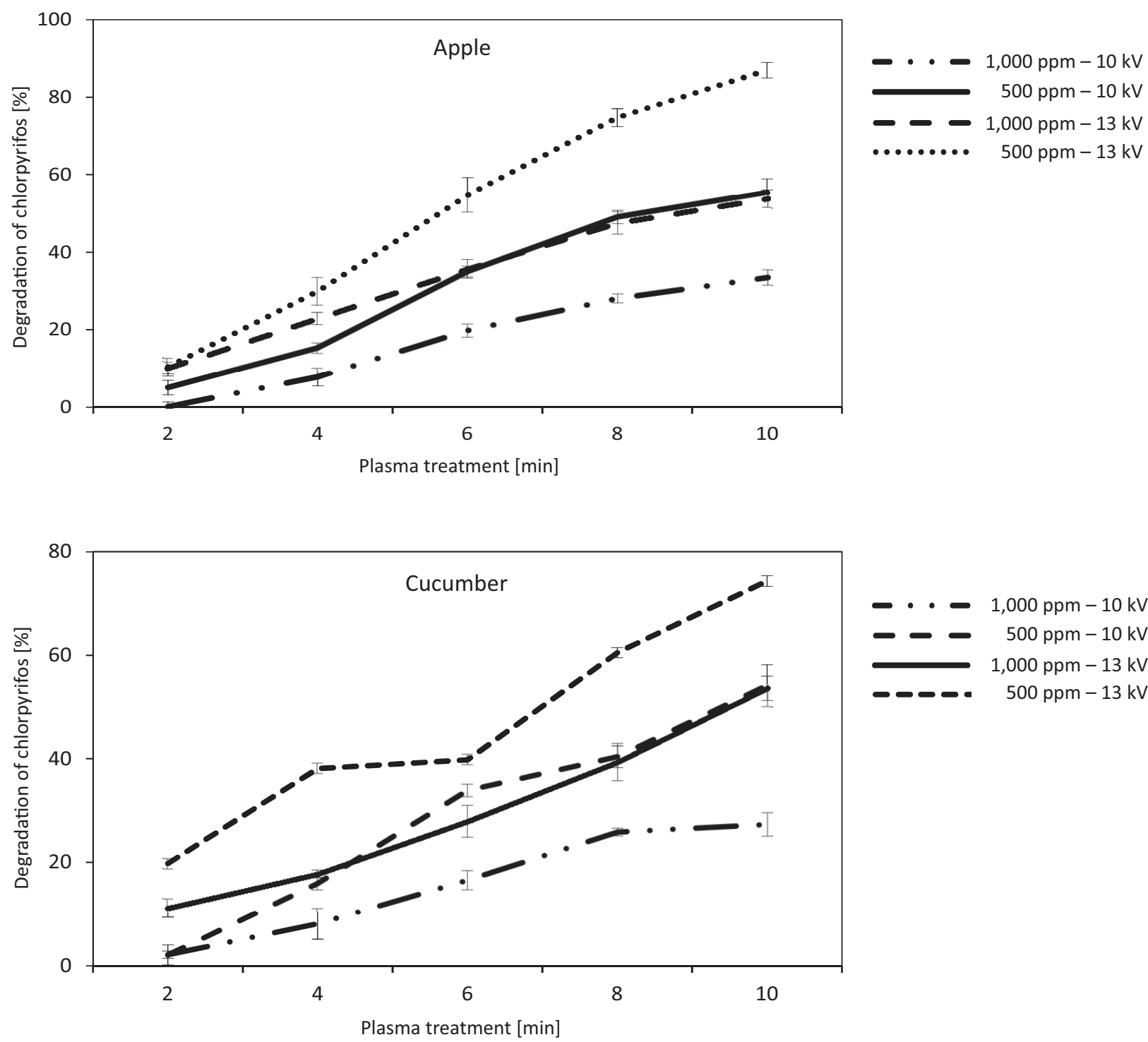

Fig. 3. Effect of the duration of cold plasma treatment on the degradation of chlorpyrifos at different voltages in apple and cucumber 


\section{Effect of cold plasma on moisture content of different products}

With increasing the time of using cold plasma from 2 to $10 \mathrm{~min}$, the mean moisture content of both products treated with cold plasma at 10 and $13 \mathrm{kV}$ decreased slightly (2-3\%) compared to control. The greatest decrease $(2.6 \%$ in apple and $3.03 \%$ in cucumber) was found for the use of cold plasma at $13 \mathrm{kV}$. Therefore, as a result, cold plasma treatment had no significant effect on the moisture content of apple and cucumber ( $p>0.05$ ). In general, the mean of moisture content of cucumber in comparison with apple was reduced by about 0.43 (Fig. 4).

\section{Effect of cold plasma on glucose content in apple}

We did not observe any changes in glucose content of apple with longer use of cold plasma. As a result, cold plasma treatment did not affect the glucose content of apple significantly ( $\mathrm{p}>0.05)$ (Fig. 5).

\section{Effect of cold plasma on texture hardness of different products}

The texture hardness of apple and cucumber with an increase in the time that cold plasma was used from 2 to $10 \mathrm{~min}$ at 10 and $13 \mathrm{kV}$ had no significant difference (1-1.5 unit) compared to the control. By using cold plasma at $13 \mathrm{kV}$, we observed the greatest decrease in texture hardness (1.75 unit in apple and 1.18 unit in cucumber) that was not significantly different from the control. According to our results, cold plasma treatment had no significant effect on texture hardness of apple and cucumber ( $p>0.05$ ) (Fig. 6).

\section{Effect of cold plasma on the color of different products}

Our results showed that cold plasma treatment had no significant effect on the color of apple and cucumber. Properties such as brightness, redness and greenness were not affected by using cold plasma on apple and cucumber $(p>0.05)$ (Fig. 7).
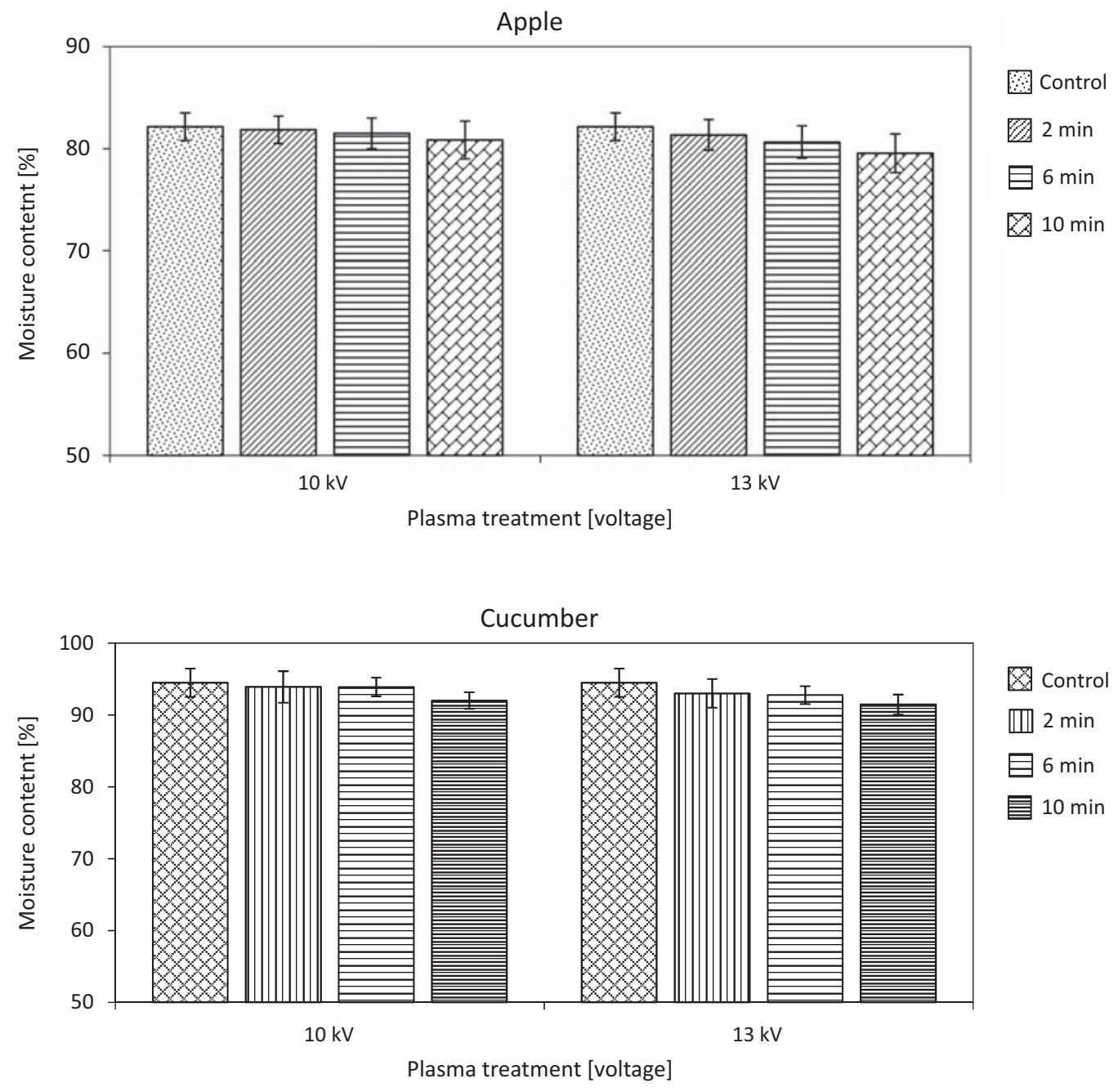

Fig. 4. Effect of cold plasma treatment on moisture content in apple and cucumber at different voltages 


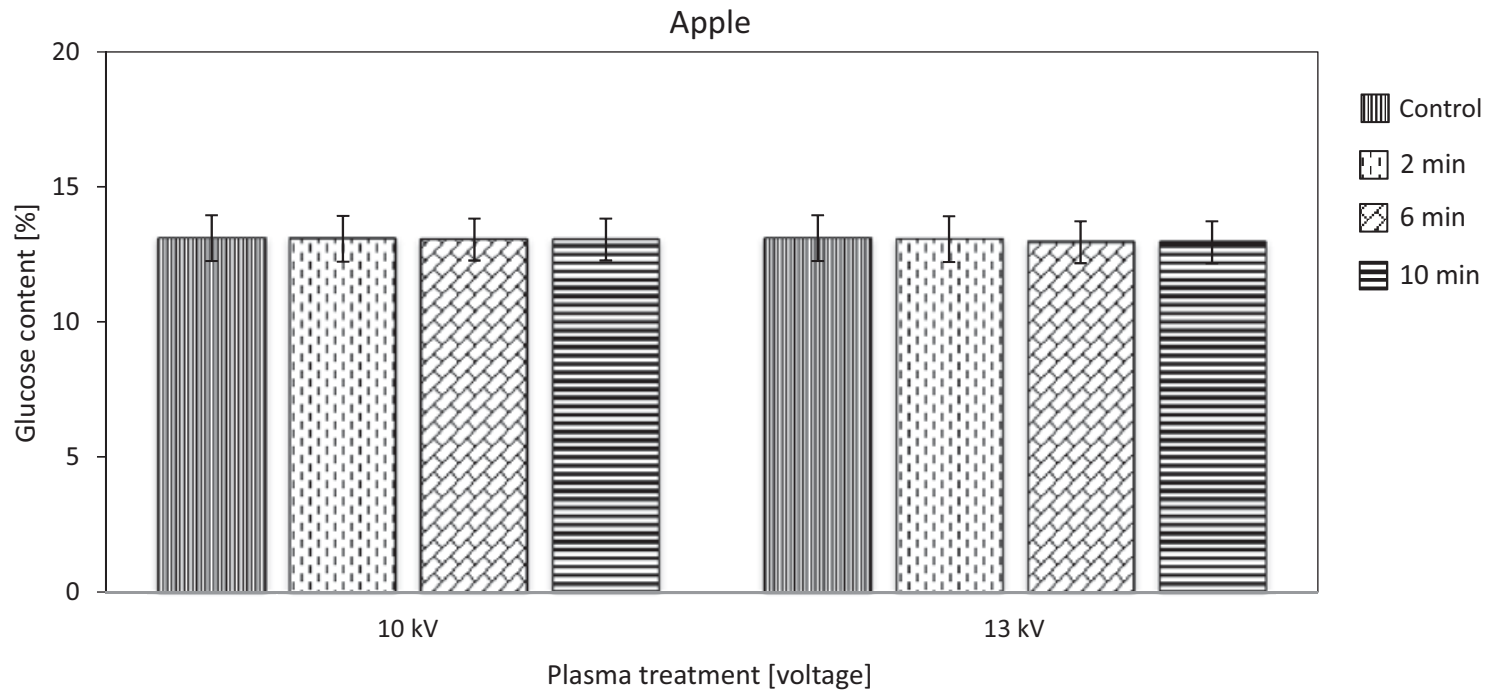

Fig. 5. Effect of cold plasma treatment on glucose content in apple at different voltages

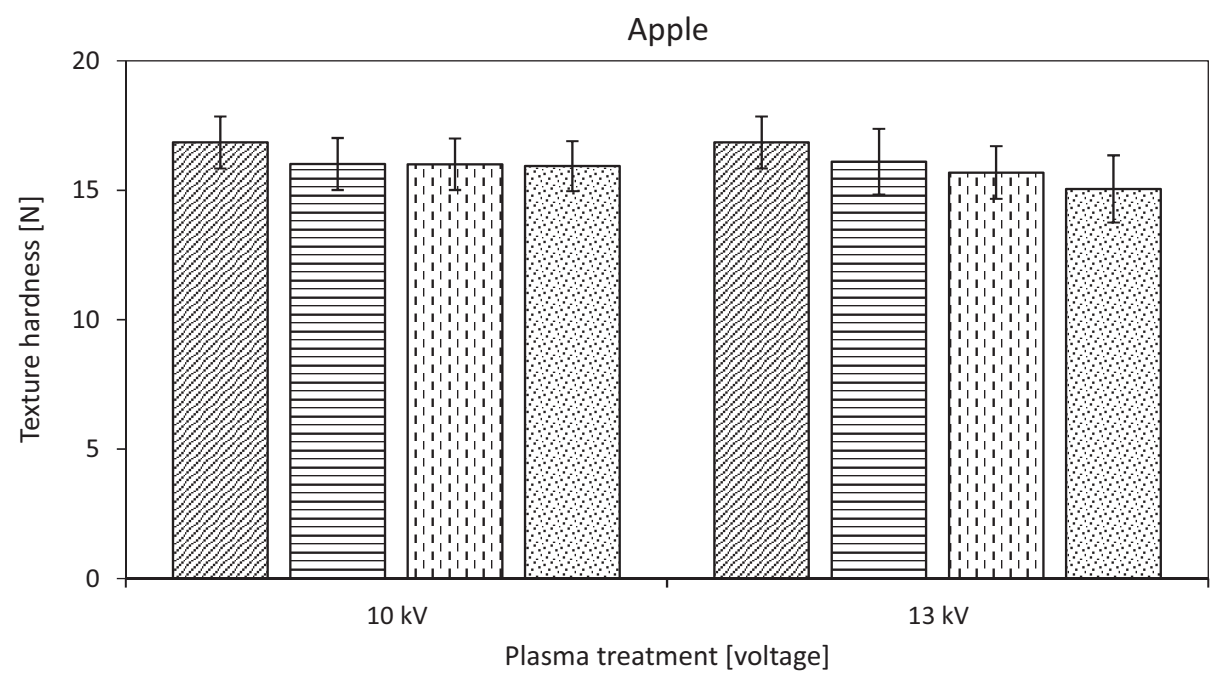

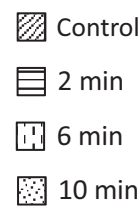

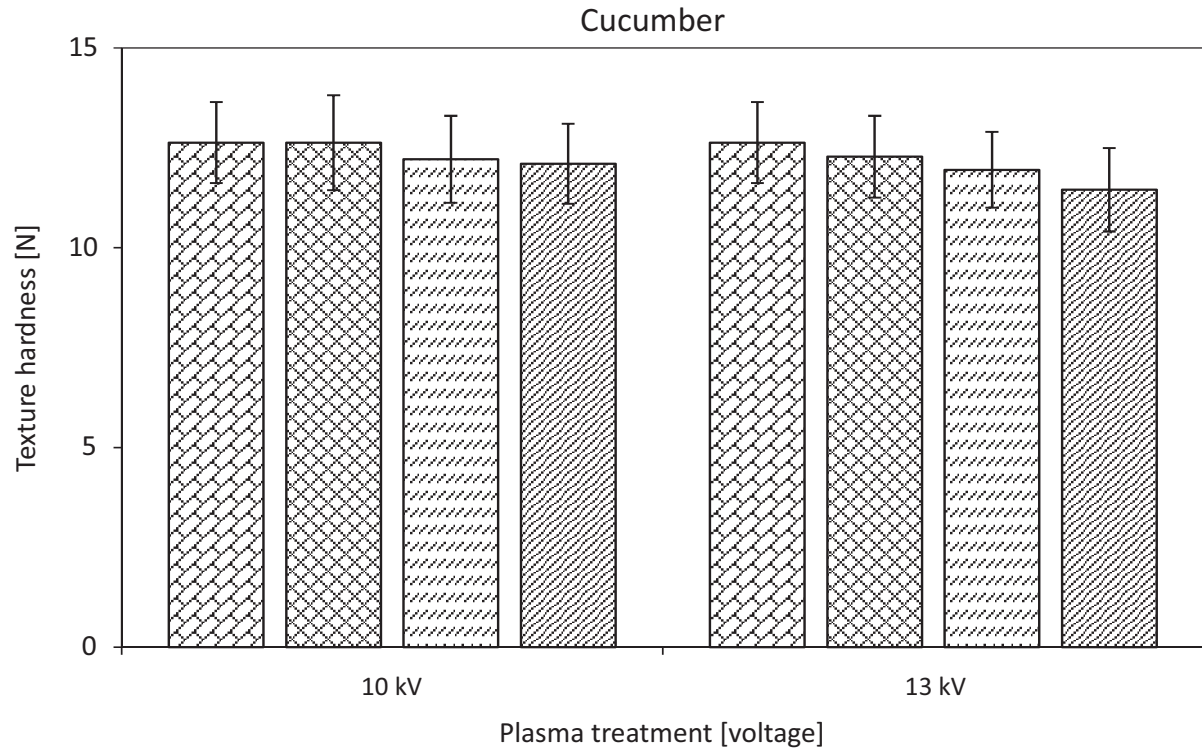

Control

$\otimes 2 \mathrm{~min}$

$6 \mathrm{~min}$

$10 \mathrm{~min}$

Fig. 6. Effect of cold plasma treatment on texture hardness in apple and cucumber at different voltages 

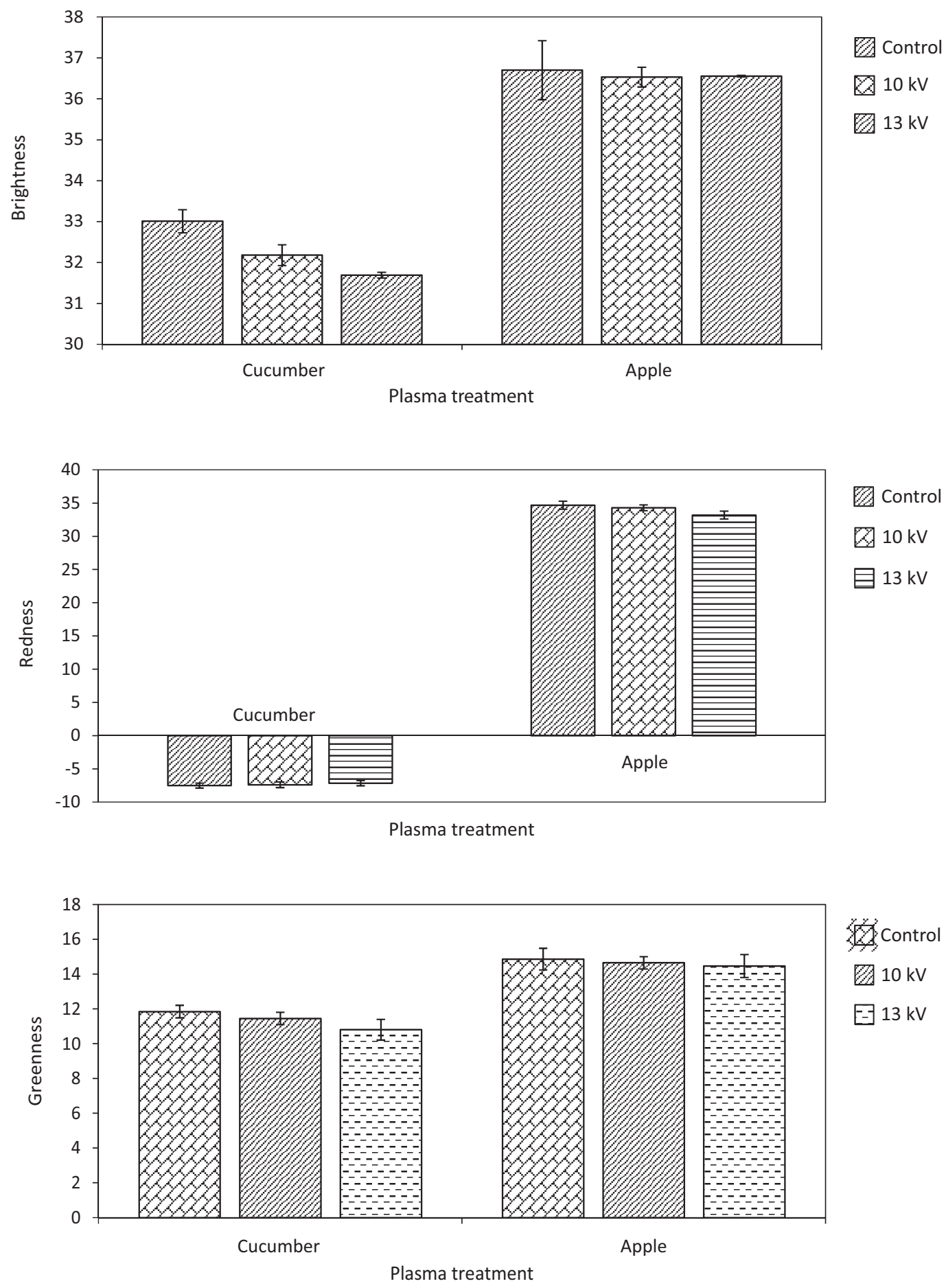

Fig. 7. Effect of cold plasma treatment on color in apple and cucumber at different voltages

\section{The results of GC/MS device}

In this research due to the insignificant amount of known metabolites, we only did a qualitative identification of metabolites with respect to the molecular weight of pesticides and their metabolites known by using GC/MS. Their names are listed below. We identified three known metabolites of diazinon [2-isopropyl-4-methoxy-pyrimidine, diazoxon and 2-Isopropyl-6-methyl-4-pyrimidinol (IMP)] and one metabolite of chlorpyrifos, 3,5,6-trichloro-2-pyridinol (TCP) by GC/MS (Fig. 8).

\section{Discussion}

The results showed that the efficiency of different factors on pesticide detoxification varied, so that the duration of plasma treatment had an important role on 

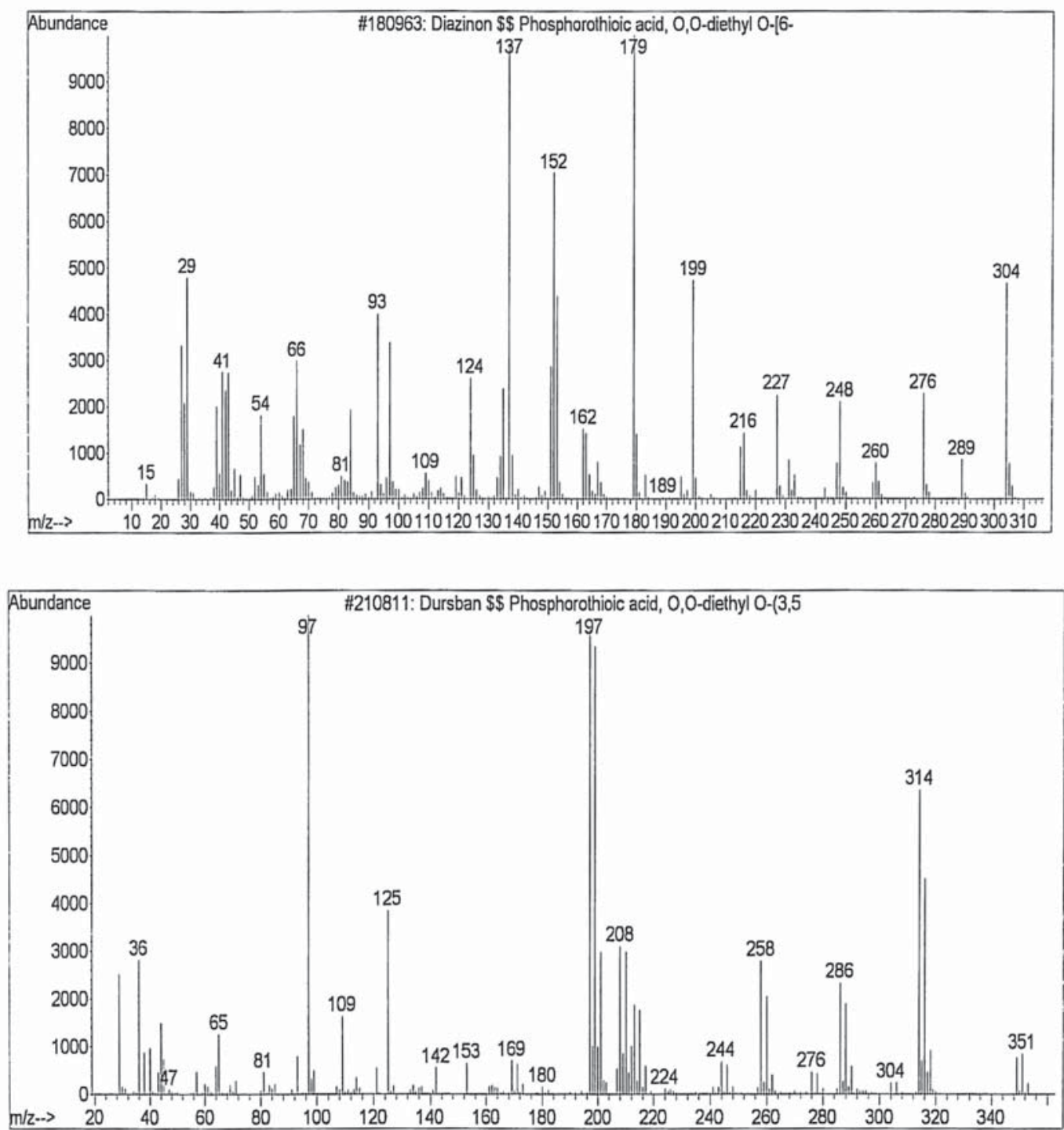

Fig. 8. Mass spectrum of diazinon and chlorpyrifos and their metabolites

detoxification. We found that as the duration of plasma treatment increased, the pesticide detoxification also increased. We observed that when the voltage of cold plasma was increased, the percentage of detoxification increased and $13 \mathrm{kV}$ was more effective than $10 \mathrm{kV}$.

The pesticides used in this research were chosen from different groups. Diazinon and chlorpyrifos are non-halogenated and halogenated, respectively. Both pesticides are not systemic and are slightly soluble in water. Our results showed that the percentages of detoxification varied according to the type of pesticide, noticeably because of differences in the chemical and physical structures of pesticides such as molecular structure, solubility in water, polarity, penetration in plant tissues and stay away from the detoxification factors. We suggested that the percentage of detoxification of diazinon was more than that of chlorpyrifos. Our findings were similar to the results of other researchers such as Li et al. (2013), Misra et al. (2014) and Reddy et al. (2014). Li et al. (2013) showed that nitenpyram (NTP) pesticide could effectively be removed from aqueous solutions by low-temperature plasma. The results of Misra et al. (2014) revealed that nonthermal plasma treatment using a dielectric barrier discharge successfully degraded pesticide residues such as azoxystrobin, cyprodinil, fludioxonil and pyriproxyfen on strawberries. The studies of Reddy et al. (2014) showed the potential of a non-thermal plasma generated in a DBD configuration for the removal of endosulfan. The percentage of degradation during the experiment at $60 \mathrm{~min}$ of plasma treatment in different concentrations of endosulfan and different voltages was between 83.6 to $85.2 \%$.

According to our results, with increasing preliminary concentrations of pesticides, the percentage of detoxification with cold plasma decreased. At high concentrations of pesticides, the production of hydroxyl radicals that cause strong oxidation and decomposition rates was reduced. On the other hand with low concentrations of pesticides more molecules of toxins 
exposed to cold plasma active oxidation agents, and result in an increase in the percentage of detoxification (Zhang et al. 2010).

We suggest that the detoxification in apple was $6 \%$ higher than cucumber. Different agricultural products have varying uptake and penetration of pesticides. In general it could be said that the pesticide accumulates in cucurbits such as cucumber, tomato, etc. more than other agricultural products. Also, because the apple has skin that is thinner than cucumber, the cold plasma active oxidation agents can penetrate more easily and more oxidation can happen than in the cucumber.

Investigation of the effect of ozone on residues of fenitrothion in lettuce, strawberry and cherry tomatoes showed that ozone could reduce the residue of the pesticide in lettuce more effectively than in the others. Cherry tomatoes have a pericarp harder than lettuce and strawberry that the dissolved ozone and free hydroxyls cannot penetrate and become inactive in contact with the skin of cherry tomatoes (Tamaki and Ikeura 2012).

The metabolites that we identified in this research were more polar and less toxic than the main pesticides. The identified metabolites, as a result of strong oxidizing agents in cold plasma, during the oxidation reaction such as hydroxylation and desulfuration (reaction) were turned into oxidized and hydroxylated compounds (Abu-Qare and Abou-Donia 2001; Kouloumbos et al. 2003; Li et al. 2015).

Our results about moisture and glucose content, the color of fruits and vegetables and texture hardness were similar to other studies. A slight decrease in the moisture content of samples treated with cold plasma resulted from air flow generated in the plasma at $30^{\circ} \mathrm{C}$, the temperature at which partial evaporation of water from the surface of products occurs. A decrease in the moisture content of agricultural products also can decrease texture hardness. On the other hand, the decrease in brightness, redness and greenness of the studied products can be explained by the fact that the hydroxyl radicals formed in the plasma do not attack the molecules selectively, therefore they can influence pigments or anthocyanins. This subject depends on the length of treatment time with cold plasma. The decrease in skin brightness of products may be caused by decreased moisture content. A slight decrease in the glucose content of apple showed that the compounds within products only change on the surface of fruit, because the plasma does not penetrate deep (Wang et al. 2012; Bermúdez-Aguirre et al. 2013; Misra et al. 2014).

\section{Conclusions}

The results revealed that treatment of samples with cold plasma considerably reduced pesticides without any harmful, toxic or other undesirable effects on the color and texture of the sample. Using plasma systems is a new way for detoxification. This method has many advantages, including the ability to detoxify at relatively low temperatures and in a short time. Another advantage is that it is non-toxic and safe for humans. The plasma used for detoxification was cold plasma, because the heavy particles (ions and neutral particles) have a lower temperature than the electrons in cold plasma. Therefore, the electrons can break the molecules and ionize the atoms and molecules of the gases without the need of heavy particles with high energy. The advantage of detoxification under atmospheric pressure is that they allow active species to be formed in abundance. Cold plasma treatment is a non-thermal technology that is used for heat-sensitive foods. Although plasma irradiation on fruits and vegetables can create desirable properties, at the same time long-term exposure may lead to a decrease in the shelf life. So, regarding the application of cold plasma on agricultural products we have to find the optimum time.

\section{References}

Abu-Qare A.W., Abou-Donia M.B. 2001. Determination of diazinon, chlorpyrifos, and their metabolites in rat plasma and urine by high-performance liquid chromatography. Journal of Chromatographic Science 39 (5): 200-204.

Ambrus A. 2009. Estimation of sampling uncertainty for determination of pesticide residues in plant commodities. Journal of Environmental Science and Health, Part B 44: 627-639.

Bai Y.H., Zhou L., Wang J. 2006. Organophosphorus pesticide residues in market foods in Shaanxi area, China. Food Chemistry 98 (2): 240-242.

Bai Y., Chen J., Mu H., Zhang C., Li B. 2009. Reduction of dichlorvos and omethoate residues by $\mathrm{O}_{2}$ plasma treatment. Journal of Agricultural and Food Chemistry 57 (14): 6238-6245.

Bai Y., Chen J., Yang Y., Guo L., Zhang C. 2010. Degradation of organophosphorus pesticide induced by oxygen plasma: effects of operating parameters and reaction mechanisms. Chemosphere 81 (3): 408-414.

Bayliss D.L., Walsh J.L., Shama G., Iza F., Kong M.G. 2009. Reduction and degradation of amyloid aggregates by a pulsed radio-frequency cold atmospheric plasma jet. New Journal of Physics 11 (11): 115024.

Bermúdez-Aguirre D., Wemlinger E., Pedrow P., Barbosa-Cánovas G., Garcia-Perez M. 2013. Effect of atmospheric pressure cold plasma (APCP) on the inactivation of Escherichia coli in fresh produce. Food Control 34 (1): 149-157.

Deng X.T., Shi J.J., Kong M.G. 2007. Protein destruction by a helium atmospheric pressure glow discharge: capability and mechanisms. Journal of Applied Physics 101 (7): 074701.

Feng H., Sun P., Chai Y., Tong G., Zhang J., Zhu W., Fang J. 2009. The interaction of a direct-current cold atmospheric-pressure air plasma with bacteria. IEEE Transactions on Plasma Science 37 (1): 121-127.

Fernández A., Thompson A. 2012. The inactivation of Salmonella by cold atmospheric plasma treatment. Food Research International 45 (2): 678-684.

Georgescu N., Lungu C.P., Lupu A. 2010. Chemical activation of the high voltage pulsed, cold atmospheric plasma jets. Romanian Reports in Physics 62 (1): 142-151.

Hernandez-Borges J., Cabrera J.C., Rodriguez-Delgado M.A. 2009. Analysis of pesticide residues in bananas harvested in the Canary Islands (Spain). Food Chemistry 113 (1): 313-319. 
Kim S.H., Kim J.H., Kang B.K. 2007. Decomposition reaction of organophosphorus nerve agents on solid surfaces with atmospheric radio frequency plasma generated gaseous species. Langmuir (the ACS Journal of Surfaces and Colloids) 23 (15): 8074-8078.

Koban I., Matthes R., Hübner N.O., Welk A., Meisel P., Holtfreter B., Sietmann R., Kindel E., Weltmann K.D., Kramer A., Kocher T. 2010. Treatment of Candida albicans biofilms with low-temperature plasma induced by dielectric barrier discharge and atmospheric pressure plasma jet. New Journal of Physics 12 (7): 073039.

Kouloumbos V.N., Tsipi D.F., Hiskia A.E., Nikolic D., van Breemen R.B. 2003. Identification of photocatalytic degradation products of diazinon in $\mathrm{TiO}_{2}$ aqueous suspensions using GC/MS/MS and LC/MS with quadrupole time-of-flight mass spectrometry. Journal of the American Society for Mass Spectrometry 14 (8): 803-817.

Le Person A., Mellouki A., Munoz A., Borras E., Martin-Reviejo M., Wirtz K. 2007. Trifluralin: photolysis under sunlight conditions and reaction with $\mathrm{HO}$ radicals. Chemosphere 67 (2): 376-383.

Li S.P., Jiang Y.Y., Cao X.H., Dong Y.W., Dong M., Xu J. 2013. Degradation of nitenpyram pesticide in aqueous solution by low-temperature plasma. Environmental Technology 34 (12): 1609-1616.

Li W., Liu Y., Duan J., van Leeuwen J., Saint C.P. 2015. UV and $\mathrm{UV} / \mathrm{H} 2 \mathrm{O} 2$ treatment of diazinon and its influence on disinfection byproduct formation following chlorination. Chemical Engineering Journal 274: 39-49.

Misra N.N., Patil S., Moiseev T., Bourke P., Mosnier J.P., Keener K.M., Cullen P.J. 2014. In-package atmospheric pressure cold plasma treatment of strawberries. Journal of Food Engineering 125: 131-138.

Misra N.N., Tiwari B.K., Raghavarao K.S.M.S., Cullen P.J. 2011. Nonthermal plasma inactivation of food-borne pathogens. Food Engineering Reviews 3 (3-4): 159-170.

Niemira B.A. 2012. Cold plasma decontamination of foods. Annual Review and Food Science and Technology 3: 125-142.

Oancea P., Oncescu T. 2008. The photocatalytic degradation of dichlorvos under solar irradiation. Journal of Photochemistry and Photobiology A: Chemistry 199 (1): 8-13.

Ormad M.P., Miguel N., Claver A., Matesanz J.M., Ovelleiro J.L. 2008. Pesticides removal in the process of drinking water production. Chemosphere 71 (1): 97-106.

Reddy P.M.K., Mahammadunnisa S., Subrahmanyam C. 2014. Catalytic non-thermal plasma reactor for mineralization of endosulfan in aqueous medium: A green approach for the treatment of pesticide contaminated water. Chemical Engineering Journal 238: 157-163.

Tamaki M., Ikeura H. 2012. Removal of residual pesticides in vegetables using ozone microbubbles. INTECH Open Access Publisher. Chapter 6. p. 113-118.

Wang R.X., Nian W.F., Wu H.Y., Feng H.Q., Zhang K., Zhang J., Zhu W.D., Becker K.H., Fan J. 2012. Atmospheric-pressure cold plasma treatment of contaminated fresh fruit and vegetable slices: inactivation and physicochemical properties evaluation. The European Physical Journal D 66 (10): 1-7.

Zhang Y., Zhang W., Liao X., Zhang J., Hou Y., Xiao Z., Chen F., Hu X. 2010. Degradation of diazinon in apple juice by ultrasonic treatment. Ultrasonics Sonochemistry 17 (4): 662-668. 